\title{
NUMERICAL MODELING OF A PUNCH PENETRATION TEST USING THE DISCRETE ELEMENT METHOD
}

Rouhollah BASIRAT ${ }^{1 *}$, Jafar KHADEMI HAMIDI ${ }^{1}$

\section{Abstract}

Understanding the brittleness of rock has a crucial importance in rock engineering applications such as the mechanical excavation of rock. In this study, numerical modeling of a punch penetration test is performed using the Discrete Element Method (DEM). The Peak Strength Index (PSI) as a function of the brittleness index was calculated using the axial load and a penetration graph obtained from numerical models. In the first step, the numerical model was verified by experimental results. The results obtained from the numerical modeling showed a good agreement with those obtained from the experimental tests. The propagation path was also simulated using Voronoi meshing. The fracture was created under the indenter in the first step, and then radial fractures were propagated. The effects of confining pressure and strength parameters on the PSI were subsequently investigated. The numerical results showed that the PSI increases with enhancing the confining pressure and the strength parameter of the rock, including cohesion and the friction angle. A new relationship between the strength parameters and PSI was also introduced based on two variable regressions of the numerical results.

\section{Address}

1 Faculty of Engineering, Tarbiat Modares University, Tehran, Iran

* Corresponding author: r.basirat@modares.ac.ir

\section{Key words}

- Punch Penetration Test,

- Indentation Test,

- Peak Slope Index

- Brittleness,

- DEM.

\section{INTRODUCTION}

Brittleness is an important rock characteristic; it is pertinent to predicting rock fragmentation behavior, energy consumption in cutting rock, and the selection of proper cutting geometry considerations in mechanical excavation (Yagiz and Rostami, 2012). According to Yagiz and Rostami (2012), while brittleness is typically well understood as a concept, there is no universally accepted measure for this rock characteristic; often a combination of rock properties is used to define brittleness rather than a single test to make a direct measurement.

One of the tests that could be considered for the measurement of brittleness is an indentation test. The punch penetration test, which was originally intended to provide a direct method for estimating the normal load on disc cutters was developed in the late 1960s to provide a direct laboratory method to investigate rock behavior under the indenter (after Handewith, 1970). This test has been used for evaluations of the hardness of rock, its drillability, and brittleness, and can be considered for predicting the performance of a Tunnel Boring Machine (TBM) (Dollinger et al., 1998; Merguerian et al., 2003; Yagiz, 2006; Jeong et al., 2012; Yagiz and Karahan, 2015; and Yagiz, 2015). Szwedzicki (1998) employed the test to measure rock hardness and stated that this test could be used for predicting the cuttability of rocks. Ozdemir (2002) stated that the test could be utilized for quantifying the brittleness and toughness of rock by using test results. Yarali (2007) found a power relation with a correlation coefficient of 0.86 between the drilling rate index (DRI) and brittleness index for fourteen different types of rock. 
Tab. 1 Equations presented for determining the brittleness of rocks

\begin{tabular}{lr}
\hline Equation & Reference \\
\hline$B_{1}=\frac{U C S}{B T S}$ & Hucka and Das (1974) \\
$B_{2}=\frac{(U C S-B T S)}{(U C S+B T S)}$ & Hucka and Das (1974) \\
$B_{3}=\sin (\varphi)$ & Hucka and Das (1974) \\
$B_{4}=U C S \times B T S / 2$ & Altindag (2002) \\
$B_{5}=0.198 \times U C S-2.174 \times B T S+0.913 \times \rho-3.807$ & Yagiz (2009) \\
$B_{6}=\sqrt{U C S \times B T S / 2}$ & Altindag (2010) \\
$B_{7}=(U C S \times B T S)^{0.72}$ & Yarali and Soyer (2011) \\
$B_{8}=\frac{U C S^{0.84}-E^{0.51}}{B T S^{0.21}}$ & Nejati and Moosavi (2017) \\
\hline
\end{tabular}

The UCS is the uniaxial compressive strength (MPa); BTS is the Brazilian tensile strength (MPa); $\varphi$ is the friction angle (degree); E is the Young's modulus (GPa); and $\rho$ is the density $\left(\mathrm{kN} / \mathrm{m}^{3}\right)$

In the punch penetration test, a standard conical indenter is pressed into a rock sample that is cast in a confining steel ring (Fig. 1). The load-displacement measurements of the indenter are then acquired with a computer system and can be related to the mechanical cuttability (the energy required for efficient chipping) of the rock.

The brittleness of the rock was defined by the different relationships between the uniaxial compressive strength (UCS), Brazilian tensile strength (BTS), and friction angle $(\varphi)$ of the intact rock. Table 1 illustrates the usual equations ( $B 1$ to $B 8$ ) for determining the brittleness index as presented by different researchers.

\section{PUNCH PENETRATION TEST}

The punch penetration test is one of the methods used for investigating various rock properties such as brittleness, toughness, hardness and drillability by utilizing different evaluation techniques. Figure 1 shows the schematics of the punch penetration test. A typical force penetration curve recorded in a laboratory is shown in Figure 2 for a hemispherical indenter penetrating a piece of low-tohigh brittle cylindrical rock confined by a steel tube. The first test apparatus was designed and the testing procedure given in a paper by Hamilton and Handewith (1971). Since then, the test has been used for different purposes and does not specify certain rock properties. In the earliest method, the test was conducted to examine the boreability of rocks via the slope of the best fit line on a force-penetration chart.

Yagiz $(2002,2009)$ suggested the peak strength index (PSI) obtained from the punch test as shown in Eq. (1).

$$
P S I=\frac{F_{\max }}{P_{\max }}
$$

where PSI is the brittleness index measured in $\mathrm{kN} / \mathrm{mm} ; F_{\max }$ is the maximum applied force on a rock sample in $\mathrm{kN} ; P_{\max }$ is the corresponding penetration at the maximum force in $\mathrm{mm}$.

\section{NUMERICAL MODELING}

The punch penetration test is simulated using the Discrete Element Method (DEM) considering various conditions. Two different models are simulated in this study:

- A simple model without any fictitious joint (quadratic meshing)

- A model with fictitious joints (Voronoi meshing)

The Voronoi blocking is used for showing the propagation of a fracture, and a simple model is used for calculating the PSI and a sensitive analysis. Kulatilake et al. (1992) found that by choosing the parameter values for the constitutive models as given below, it is possible to make the fictitious joints behave like the intact rock, in a global sense:

(a) the same strength parameter values should be used for both the intact rock and the fictitious joints;

(b) a joint shear stiffness (JKS) value for fictitious joints should be chosen to produce a shear modulus JKS ratio $(\mathrm{G} / \mathrm{JKS})$ between 0.008 and 0.012 ;

(c) a joint normal stiffness/JKS ratio (JKN/JKS) between 2 and 3 should be chosen. The most appropriate value in this range may be Young's modulus/G value $(\mathrm{E} / \mathrm{G})$ for this particular rock.

The configuration of the computational models and boundary conditions are shown in Figure 3. The dimension of the model is $54 \times 54$ $\mathrm{mm}$. The indenter load is modelled by a normal velocity with the rate of $2.54 \times 10^{-3} \mathrm{~mm} / \mathrm{sec}$ applied at the middle of the upper boundary through a contact thickness of $2.5 \mathrm{~mm}$. The lower boundary is regarded as a fixed displacement boundary, and the left and right boundaries are fixed in the $\mathrm{x}$ direction. The rock block is discretized with fine finite difference meshes, namely zones in UDEC. The zone size in the blocks is set at $2.5 \mathrm{~mm}$.

\subsection{Verification of the numerical model}

The model was verified in comparison with the experimental results obtained from a study by Jeong et al. (2015). The rock types used in their study in Korea are Macheon granite and Sungnam 
gneiss, which are generally classified as hard rock with uniaxial compressive strengths of about $100 \mathrm{MPa}$. The ratio of the UCS to the BTS, which usually indicates the brittleness of rock, ranges from 6 to 22. The rock mechanical properties are given in Table 2. The behavior model is considered under the Mohr-Coulomb criteria.

Tab. 2 Mechanical properties of the rock samples tested for verification

\begin{tabular}{|l|l|l|l|}
\hline Properties & Unit & $\begin{array}{l}\text { Macheon } \\
\text { granite }\end{array}$ & $\begin{array}{l}\text { Sungnam } \\
\text { gneiss }\end{array}$ \\
\hline Uniaxial compressive strength & $\mathrm{MPa}$ & 107.61 & 91.53 \\
\hline Brazilian tensile strength & $\mathrm{MPa}$ & 7.43 & 15.18 \\
\hline Young's modulus & $\mathrm{GPa}$ & 71.0 & 75.3 \\
\hline Density & $\mathrm{gr} / \mathrm{cm}^{3}$ & 2.85 & 2.72 \\
\hline Poisson's ratio & - & 0.18 & 0.15 \\
\hline
\end{tabular}

Figure 4 shows the displacement vector for the verification model. The penetration is monitored by defining the displacement history under a normal load. Figure 5 illustrates the normal load-penetration history during a test for the two samples. As seen in the figure, the axial point load increases till failure occurs (approximately 0.5-0.6 $\mathrm{mm}$ ). The results, which are given in Table 3 , indicate that the numerical model has a good agreement with the experimental results.

Tab. 3 Comparison between the experimental and numerical results for the two samples

\begin{tabular}{|c|c|c|}
\hline $\begin{array}{c}\text { Experimental Value } \\
(\mathrm{kN} / \mathrm{mm})\end{array}$ & $\begin{array}{c}\text { Numerical Result } \\
(\mathrm{kN} / \mathrm{mm})\end{array}$ & $\begin{array}{c}\text { Difference with the } \\
\text { average value (\%) }\end{array}$ \\
\hline 31.75 & 33.31 & 4.9 \\
\hline 39.31 & 40.28 & 2.5 \\
\hline
\end{tabular}

\subsection{Fracture propagation}

The fracture propagation is simulated based on the fictitious joint technique and by using Voronoi blocking. Figure 6 demonstrates the propagation of fractures in the model during the test. Here, the intent of the fracture propagation is when a slip in the block contacts happens. It is clear that the path of the fracture follows the fictitious joint Therefore, the block size (Voronoi meshing) is considered in a small size. According to Figure 6, the fracture is initiated from a point under the normal load; then the radial fractures are formed.

\section{SENSITIVE ANALYSIS}

\subsection{Confining pressure}

One advantage of numerical modeling is a parametric study for studying the effect of different parameters when testing is expensive and time consuming. The confining pressure is typically neglected in experimental tests. The confining pressure is an important parameter because excavation is normally performed in the presence of confining pressure in the ground. In this study, the effect of the confining pressure is investigated by using numerical modeling. For this purpose, the left and right boundaries are changed, and the horizontal stress is applied on the boundaries (Figure 7). A simple model with quadratic meshing is used for the modeling, because the computational time is quite huge (more than 200 million cycles) in the Voronoi meshing.

Five different values are considered for the pressure, including 2, 4, 6, 8, and $10 \mathrm{MPa}$. Figure 8 shows the effect of the confining pressure on the PSI. According to Figure 8, the PSI (or brittleness) directly increases when increasing the confining pressure. Since the confining pressure is enhanced by increasing the depth, it indicates that the brittleness increases in the depth.

This result is in good agreement with that reported by other researchers. Cook et al. (1984) conducted a series of indentation tests using flat-bottomed circular punches to load the flat surfaces of a rock sample and presented similar results. As the confining stress increases, tensile failure is restricted to a region adjacent to the punch corners; with the confining pressure decreasing, this region extends downwards in an approximately vertical direction as the punch load increases. Liu et al. (2002) showed that by increasing the confining pressures, a small but noticeable increase in the indentation strength was measured. During the simulation, they found that the lateral pressure had an important effect on the formation of side cracks, which are considered to be responsible for the rock fragmentation in indentation. Ma et al. (2011) simulated a rock fragmentation mechanism under a TBM cutter using RFPA ${ }^{2 \mathrm{D}}$. They found that the higher the confining ratio, the larger the chipping force is required for the rock failure. With an increase in the confining stress, the chipping force rapidly increases under a low confining stressed condition, e.g., the increment of the chipping force is $46.9 \%$ when the confining ratio $\left(\zeta=\right.$ confining pressure $\left./ \sigma_{c}\right)$ increases from 0 to 0.1 , while only a $1.2 \%$ increment is obtained when the confining ratio $(\zeta)$ increases from 0.5 to 0.6 , which means that the effect of high confining stress on the chipping force is much less than that of low confining stress. Yin et al. (2014) stated that the force for crack initiation and the crushed zone size increases with an increase in the confining stress for granite rock in a rock indentation test by a TBM cutter.

\subsection{Strength parameters}

In this section, the effect of rock strength parameters, including cohesion and the friction angle, was investigated. Figure 9 shows the relation of the cohesion and friction angle versus the PSI. A new brittleness index based on the best correlation between the cohesion, friction angle, and PSI according to Eq. (2) is:

$$
P S I=1.35 \times C+224.11 \times \sin \varphi-127.15 ; r^{2}=0.96
$$

where PSI, C, and $\varphi$ are the peak strength index $(\mathrm{kN} / \mathrm{mm})$; cohesion (MPa); and the friction angle (degree) of the rock, respectively. It is clear that the PSI increases linearly with the enhancing of the strength parameters, because the material stiffness is increased. Therefore, the required load per unit penetration is increased by enhancing the cohesion and friction angle.

These results are approved by Yagiz (2009) and Dollinger et al. (2000) in a lab environment. Their results concerning the correlations run between the physical properties of the rocks and the punch test parameters show that the strongest correlations exist between the unconfined compressive strength of the rocks and most of the punch test parameters measured.

\subsection{The relationship between brittleness indices and PSI}

The different brittleness indices were presented above in Section 2. According to the Mohr-Coulomb criterion, the uniaxial compressive strength $\left(\sigma_{c}\right)$ can be calculated using the friction angle $(\phi)$ and cohesion $(\mathrm{C})$ with the following equation:

$$
\sigma_{c}=\frac{2 C \cos (\varphi)}{1-\sin (\varphi)}
$$


Therefore, various brittleness indices were developed based on different BTS and UCS parameters. The relationship between the brittleness indices (index 1 to 8) and PSI is illustrated in Figure 10. The best correlation between PSI and brittleness is also presented in this figure. As can be seen in the figure, the PSI is enhanced by increasing the brittleness indices.

\section{CONCLUSION}

In this study, numerical modeling of a punch penetration test was performed using the discrete element method (DEM). The Peak Strength Index (PSI) as a function of the brittleness index was calculated using the axial load and a penetration graph obtained from numerical models. The numerical model was verified by the experimental results. The results obtained from the numerical modeling showed a good agreement with those from the experimental tests. Next, the propagation path was simulated using Voronoi meshing. The fracture was created under the indenter in the first step, and the radial fractures were subsequently propagated.

Then, the numerical results were compared with the various brittleness indices introduced by different researchers. It showed that the PSI enhances by increasing the brittleness indices. The effect of the confining pressure and strength parameters on the PSI were investigated. The numerical results showed that the PSI linearly increases by enhancing the confining pressure and strength parameters. Then, a new relationship between the strength parameters and PSI was also introduced based on the two variable regressions of the numerical results.

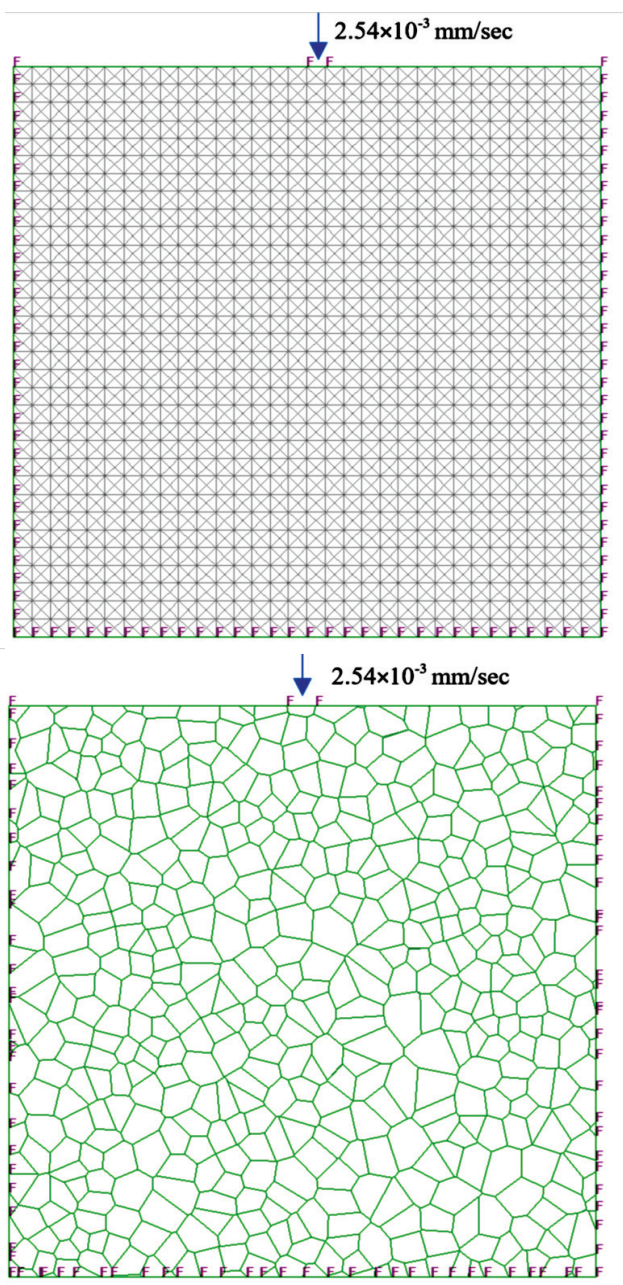

Fig. 3 The simple model with quadratic meshing and Voronoi blocking model

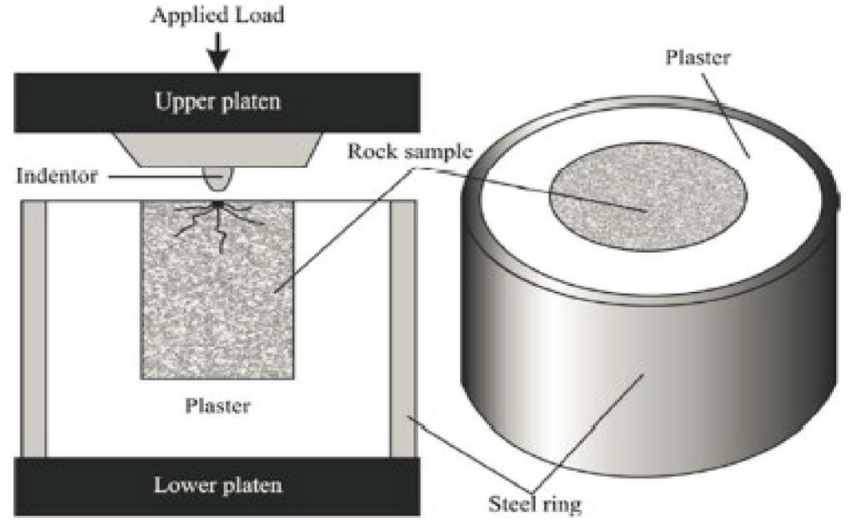

Fig. 1 Schematic of the punch penetration test (Yagiz, 2009)

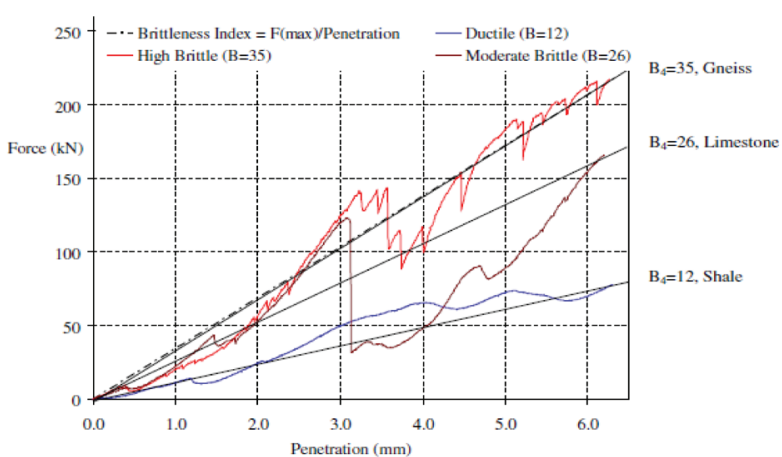

Fig. 2 Typical load vs. penetration depth curve obtained in punch penetration tests for low to high brittle rock (Yagiz, 2009)

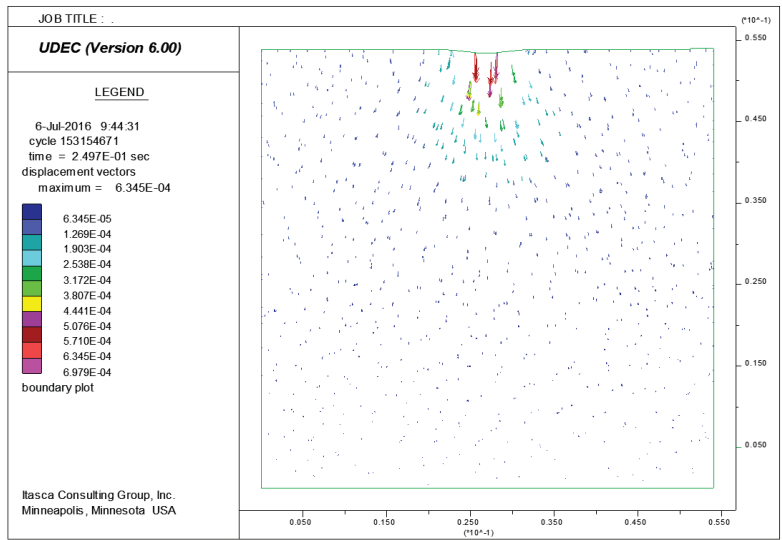

Fig. 4 Displacement vector in the verification model

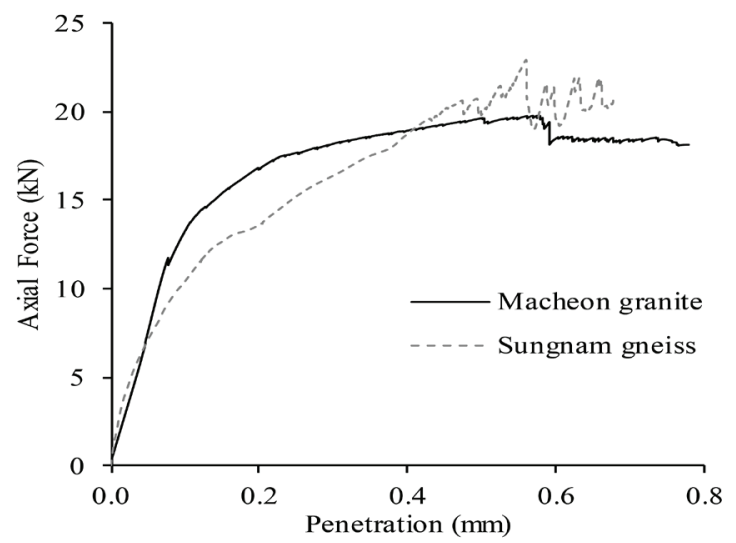

Fig. 5 The normal load-penetration history during the test for two samples 

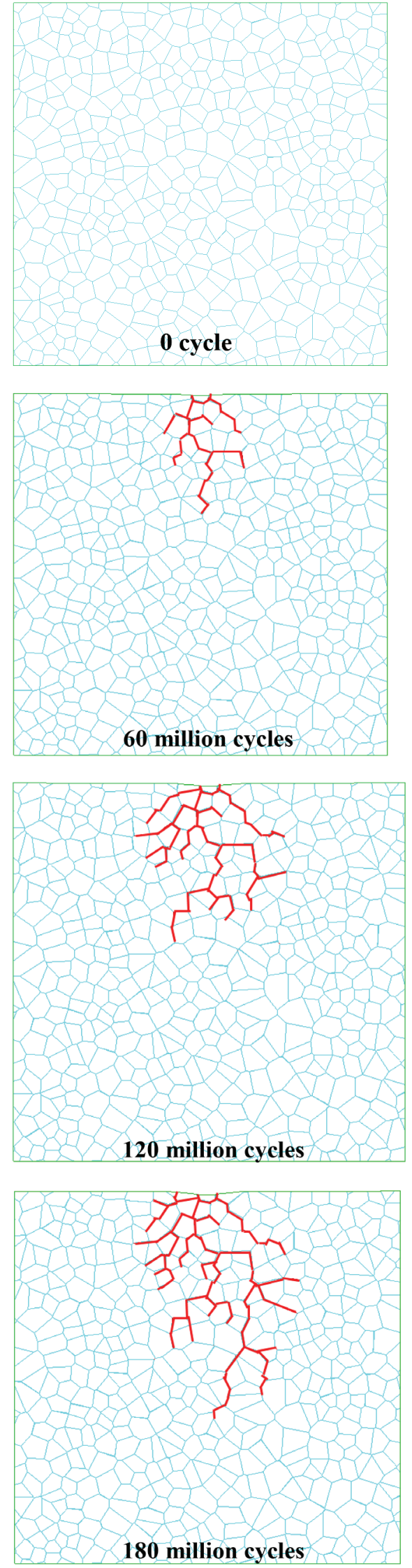
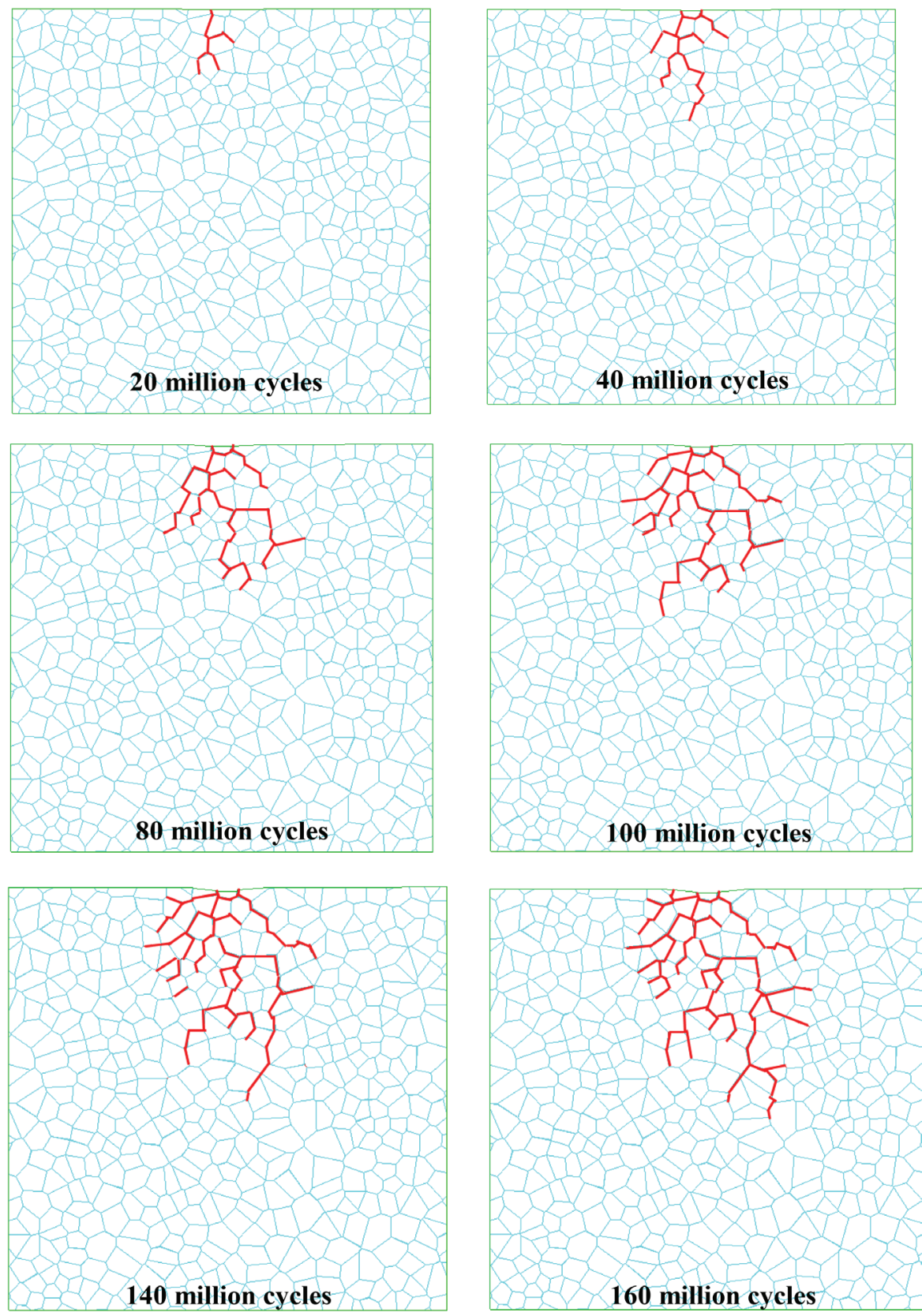

Fig. 6 Propagation of fractures in the model during the test

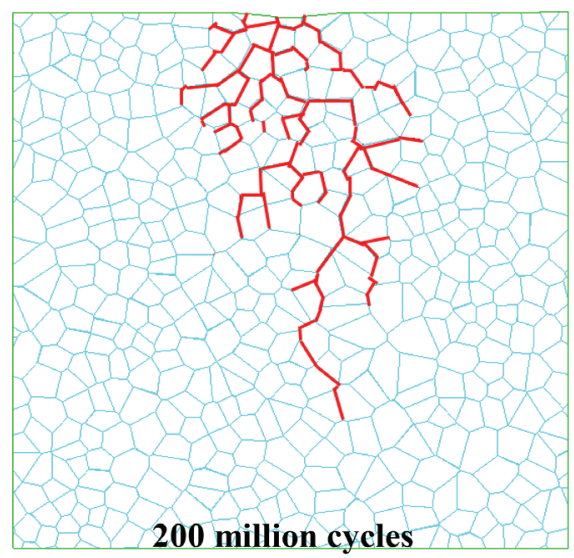




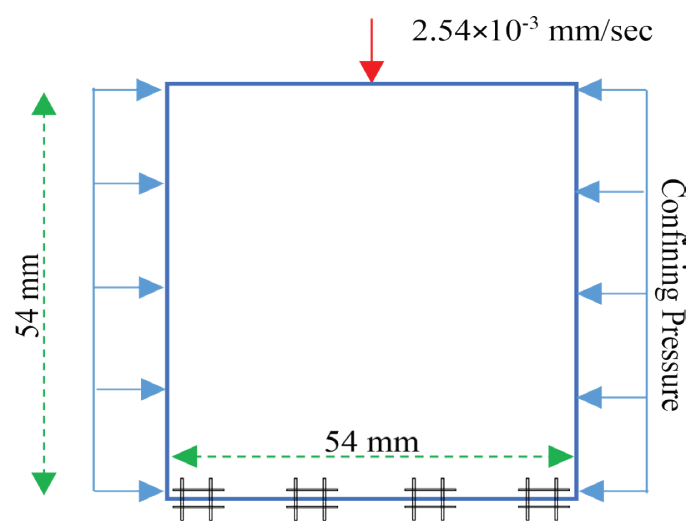

Fig. 7 Boundary condition (applying confining pressure)

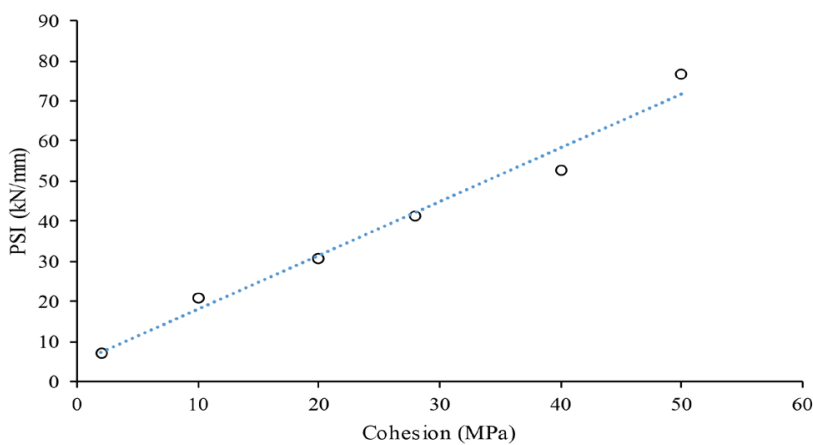

Fig. 9 The effect of cohesion and friction angle on the PSI

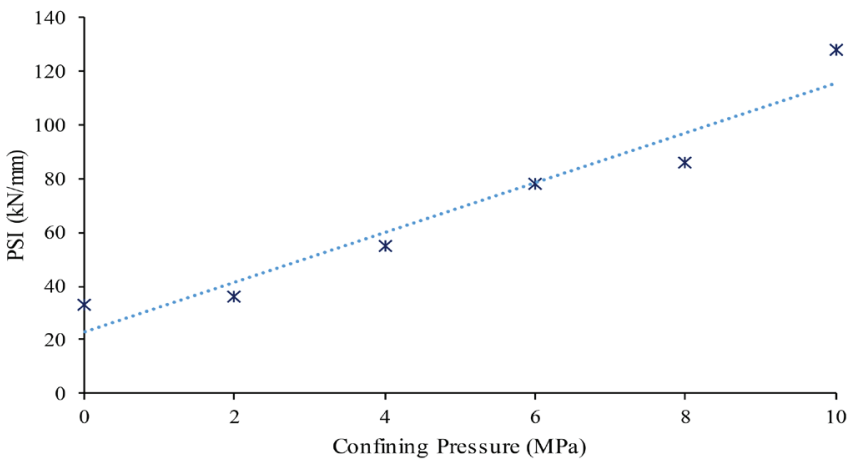

Fig. 8 The effect of confining pressure on the PSI

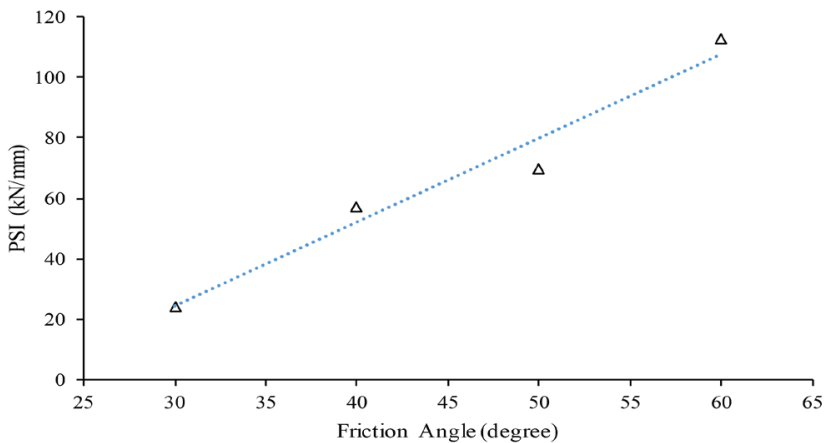

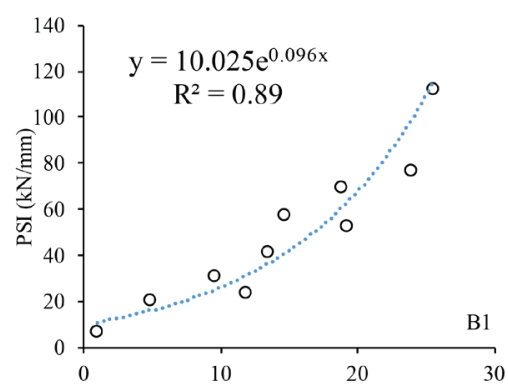
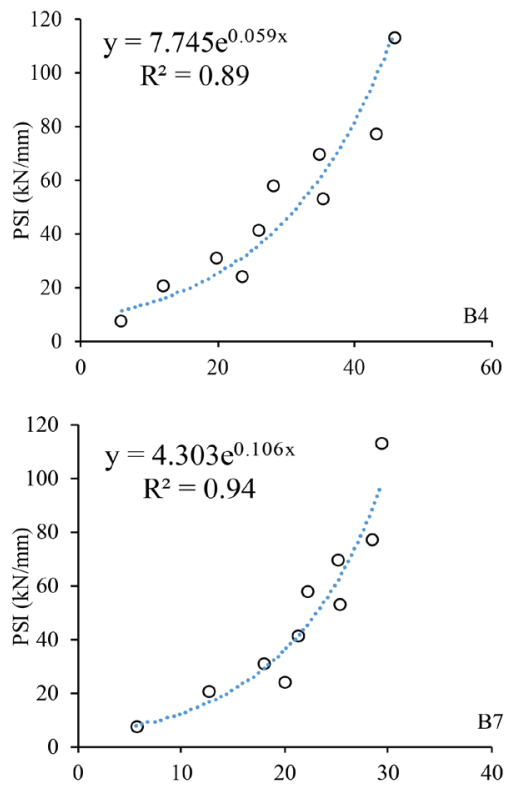
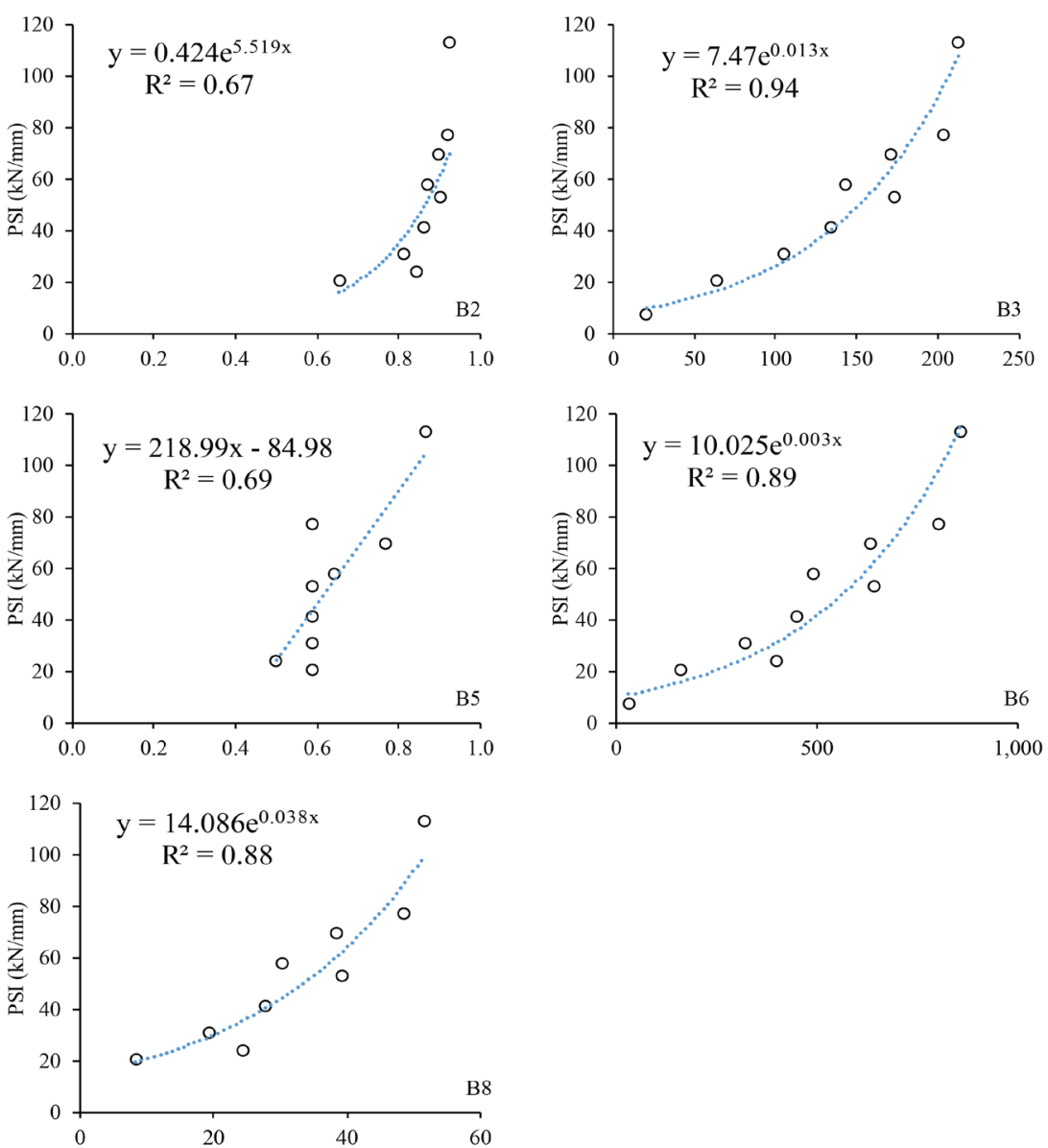

Fig. 10 The PSI versus different brittleness indice 


\section{REFERENCES}

Altindag R (2002) The evaluation of rock brittleness concept on rotary blast hole drills. J South African Inst Min Metal 102:61-66.

Altindag R (2010) Assessment of some brittleness indexes in rock-drilling efficiency. Rock Mech Rock Eng. 43:361-370.

Cook, N. G. W. - Hood, M. - Tsai, F. (1984) Observations of crack growth in hard rock loaded by an indenter. Int J Rock Mech Min Sci Geomech Abstr; 21(2):97-107. DOI: 10.1016/01489062(84)91177-X.

Dollinger, G. L. - Handewith, J. H. - Breeds, C. D. (1998) Use of Punch Tests for Estimating TBM Performance. Tunnelling and Underground Space Technology. 13, 14, 403-408. DOI: 10.1016/S0886-7798(98)00083-2.

Dollinger, G. L. - Howard, J. - Handewith, J. H. (2000) Correlations between punch test results and rock physical properties, Pacific Rocks 2, Breeds \& Doe (eds), Balkema, Rotterdam, The Netherlands, ISBN 9058091554.

Hamilton H.W. - Handewith, H. J. (1971) Apparatus and method for testing rock. United State Patent Office, No: 3618369.

Handewith, H. J. (1970) Predicting the economic success of continuous tunneling and hard rock. In: 71st Annual General Meeting of the CIM 63; 595-599.

Hucka, V. - Das, B. (1974) Brittleness determination of rocks by different methods. Int J Rock Mech Min Sci 11:389-392. DOI: 10.1016/0148-9062(74)91109-7.

Jeong, H. Y. - Jeon, S. - Cho, J. W. (2012) A Study on Punch Penetration Test for Performance Estimation of Tunnel Boring Machine, Tunnel \& Underground Space, Vol. 22, No. 2, pp. 144-156, Journal of Korean Society for Rock Mechanics. DOI: 10.7474/TUS.2012.22.2.144.

Jeong, H. Y. - Cho, J.W. - Jeon, S. - Rostami, J. (2015) Performance Assessment of Hard Rock TBM and Rock Boreabili-ty Using Punch Penetration Test, Rock Mech Rock Eng. DOI: 10.1007/s00603-015-0834-7.

Kulatilake, P. H. S. W. - Ucpirti, H. - Wang, S. - Stephansson, O. (1992) Use of the discrete element method to perform stress analysis in rock with non-persistent joints and to study the effect of joint geometry parameters on the strength and deformabili-ty of rock masses. J.Rock Mech Rock Eng. 25,253-274. DOI: 10.1007/BF01041807.

Liu, H. Y. - Kou, S. Q. - Lindqvist, P. A. - Tang, C. A. (2002) Numerical simulation of the rock fragmentation process induced by indenters. International Journal of Rock Mechanics \& Mining Sciences, vol. 39, 491-505. DOI: 10.1016/S1365-1609(02)00043-6.

Ma, H. - Yin, L. - Ji, H. (2011) Numerical study of the effect of confining stress on rock fragmentation by TBM cutters. International Journal of Rock Mechanics \& Mining Sciences 48, 1021-1033. DOI: 10.1016/j.ijrmms.2011.05.002.
Merguerian, Ch. - Ozdemir, L. (2003) Rock Mass Properties and Hard Rock TBM Penetration Rate Investigations, Queens Tunnel Complex, NYC Water Tunnel \#3, Stage 2: pp. 1019-1036 in Robinson, R.A. and Marquardt, J.M., eds., Rapid Excavation and Tunneling Conference.

Nejati, H. R. - Moosavi, S. A. (2017) A new brittleness index for estimation of rock fracture toughness. J Min Environ. 8:83-91.

Ozdemir, L. (2002) Personnel communication, Earth Mechanics Institute of Colorado School of Mines, Golden, CO, USA.

Szwedzicki, T. (1998) Draft ISRM suggested method for determining the indentation hardness index of rock materials. Int. J. Rock Mech. Min. Sci. 35 (6), 831-835.

Yagiz, S. (2002) Development of rock fracture and brittleness indices to quantify the effects of rock mass features and toughness in the CSM model basic penetration for hard rock tunneling machines. Dissertation, Colorado School of Mines, USA.

Yagiz, S. (2006) A model for the prediction of tunnel boring machine performance, IAEG2006 Paper No. 383.

Yagiz, S. (2009) Assessment of brittleness using rock strength and density with punch penetration test. Tunnelling and Underground Space Technology, 24 (1): 66-74. DOI: 10.1016/j. tust.2008.04.002.

Yagiz, S. - Rostami, J. (2012) Indentation test for the measurement of rock brittleness, 46th U.S. Rock Mechanics Geomechanics Symposium, Chicago, IL, USA, Vol.: ARMA 12-270.

Yagiz, S. (2015) The Punch Penetration Test for Estimating Machine Performance, International No-Dig İstanbul, 33rd International Conference and Exhibition.

Yagiz, S. - Karahan, H. (2015) Application of various optimization techniques and comparison of their performances for predicting TBM penetration rate in rock mass. International Journal of Rock Mechanics and Mining Sciences, 80:308e15. DOI: 10.1016/j. ijrmms.2015.09.019.

Yarali, O. (2007) Investigation of the relations between rock brittleness and drilling rate index. [In:] Proceedings of the 20th International Mining Congress of Turkey (in Turkish), Ankara, Turkey, 217-224.

Yarali, O. - Soyer, E. (2011) The effect of mechanical rock properties and brittleness on drillability. Scientific Research and Essays, 6 (5), 1077-1088.

Yin, L. J. - Gong, Q. M. - Ma, H. S. - Zhao, J. - Zhao, X. B. (2014) Use of indentation tests to study the influence of confining stress on rock fragmentation by a TBM cutter, International Jour-nal of Rock Mechanics \& Mining Sciences 72, 261-276. DOI: 10.1016/j.ijrmms.2014.07.022. 